\title{
Understanding and Improving Managers' Responses to Employee Depression
}

\author{
ANGELA MARTIN \\ University of Tasmania \\ CYNTHIA D. FISHER \\ Bond University
}

Depression is a common mental health disorder, estimated to affect between 20\% and $55 \%$ of adults in their lifetime, and has recently overtaken heart disease as the leading cause of disability (WHO, 2011). Although managers often believe that mental illness is not their concern or does not exist in their organization, working with an employee with depression is a job demand that most managers are likely to face eventually. As noted in Santuzzi, Waltz, Finkelstein, and Rupp's (2014) focal article, depression is an "invisible disability" that sufferers may be reluctant to disclose because of self- and other stigma. In one large-scale survey, only about $30 \%$ of American employees said they would feel comfortable discussing depression with their supervisor (Charbonneau et al., 2005). In this commentary, we highlight performance-related social cognitions associated with disclosed or nondisclosed depression and suggest ways in which industrial-organizational (I-O) psychologists can assist organizations to improve the management of employee depression.

Correspondence concerning this article should be addressed to Angela Martin.

E-mail: angela.martin@utas.edu.au

Address: The Tasmanian School of Business and Economics, University of Tasmania, Hobart 7000, Australia.

\section{Impact of Employee Depression on Organizations}

Individuals with depression typically experience poor concentration, decreased motivation, restlessness, irritability, fatigue, and reduced decision-making capacity (Kessler et al., 2008). Multiple dimensions of job performance are impaired by depression, including innovation, interpersonal relationships with customers and coworkers, time management, and workplace safety and vigilance. A recent meta-analysis showed that psychological health is a moderate to strong correlate of work performance (Ford, Cerasoli, Higgins, \& Decesare, 2011). Across all health conditions, depression has the largest effect on individual work performance (Kessler et al., 2008). Mood disorders (including major depressive disorder) are associated with an estimated 28-30 days of lost productivity per person per year (Tsuchiya et al., 2012). The impact worsens as the severity of depression increases (Jain et al., 2013), with every one point increase in a measure of depression (PHQ-9) being associated with an additional 1.65\% productivity loss. Even minor levels of depression are associated with decrements in work function (Beck et al., 2011). Hence, there is a strong business case for employers to invest in effective remediation for depressed employees across the continuum of depression severity. Managers 
are at the front line of detecting depression among their employees, promoting help seeking, and organizing and monitoring job accommodations. How effectively these processes play out depends on (a) the surrounding organizational context, (b) managers' attitudes and knowledge about depression, and (c) managers' capabilities and skills for acting on their knowledge.

\section{Understanding the Dynamics of (Non) Disclosure, Social Cognition, and Stigma}

If individuals do not disclose their depression to their employer, either because they deny the problem or fear the costs of disclosure, they are unlikely to receive support or accommodation from work sources. Attempting to deal with a full load of work demands may impede recovery and further reduce performance (Plaisier et al., 2012). In addition, the depressed individual's reputation is likely to suffer both among their coworkers and with their manager. The behavioral manifestations of depression mentioned above are likely to be attributed to internal causes such as reduced effort or commitment and therefore produce negative attitudes toward the depressed person.

In the absence of any specific information to the contrary, managers and coworkers are likely to apply their typical schemas for understanding and explaining performance. In the case of a previously effective employee categorized into the "good performer" schema, the first few behaviors that are out of character are likely to be forgiven as isolated incidents ("He must have gotten up on the wrong side of the bed this morning," "Perhaps she's just tired") and will not stimulate recategorization. As the number of incidents that are inconsistent with the previous good performer categorization increase, abrupt and discontinuous changes in appraisal may occur as the employee is recategorized into the "poor performer" schema. Hanges, Braverman, and Rentsch (1991) have shown that this can be modeled as a cusp catastrophe process and that one of the triggers is a shift to an internal attribution for the employee's poor work behavior. Reb and Greguras (2010) also demonstrated that a trend of declining performance over time results in stronger attributions to (lack of) effort. Once these attributions and recategorizations are made, attendance, performance, and behavioral problems are likely to result in conflict and social exclusion by coworkers and be addressed under the organization's performance management system by supervisors, thus creating additional stress for the depressed employee.

If depression is disclosed, greater accommodation and assistance is possible, assuming managers have the desire, knowledge, and skill to respond effectively. However, disclosure may also produce stigmatizing attitudes among managers and any coworkers who are informed. Research comparing explicit and implicit attitudes toward depression shows that implicit but not explicit attitudes are more negative than attitudes toward physical illness and that depression is seen as less stable and more blameworthy than physical illnesses (e.g., Monteith \& Pettit, 2011). In terms of explicit attitudes and beliefs, large-scale surveys in four European nations found that on average, $35 \%$ of respondents believed that depressed people could "snap out of it they wanted to," and 31\% characterized depression as a personal weakness (Coppens et al., 2013).

An Australian survey of managers' attitudes toward depressed employees found more positive attitudes among managers who were female, more educated, in the public sector, and less stressed themselves (Martin, 2010). As might be expected (Balcetis \& Dunning, 2008), less stigmatizing attitudes toward the depressed were reported by those who had "walked a mile in their moccasins." Specifically, Martin (2010) found that personal experience of having been depressed, having a close friend or family member with depression, or having worked with an employee who was depressed in the past was associated with less managerial stigma toward depressed 
employees. On the other hand, and consistent with the attributional explanation advanced above, managers with a strong internal locus of control seemed to project this on to depressed employees, holding them more personally accountable for their problems and thus adopting more negative attitudes (Martin, 2010).

\section{Helping Organizations Improve the Management of Employees With Depression}

A multilevel, multipronged approach is needed to facilitate the effective management of employees with depression. I-O psychologists can contribute by developing, delivering, and evaluating researchinformed interventions designed to reduce stigma and stereotyping throughout the organization; promote early and safe disclosure of depression; and enable managers to provide appropriate and supportive accommodation.

\section{Improving Organizational Context}

Individuals are influenced by social norms and organizational climate. Martin (2010) found that managers' stigmatizing attitudes toward depressed employees were stronger when the organization lacked a mental health strategy and was perceived as having a climate unsupportive of depression disclosure. Presumably, employees would also be less likely to disclose and get the help they need if they perceived an unsupportive mental health climate. This suggests organizational levers to improve the context for all managers and employees who may encounter depression in themselves or their colleagues. For instance, top leaders should model positive beliefs and actions about accommodating all forms of disabilities, including invisible ones, and should assure that explicit and supportive organizational policies regarding mental health disabilities are adopted and publicized. Employees and their managers should have access to resources such as employee assistance plans, rehabilitation specialists, and knowledgeable human resource managers when the need to deal with depression arises. As described below, organization-wide training to improve attitudes and knowledge about depression at work may also be helpful.

Improving Manager and Employee

Attitudes and Knowledge About Depression

Szeto and Dobson (2010) reviewed a number of workplace training programs aimed at reducing the stigma of mental illness at work and point out the need for research to improve the content and effectiveness of such programs. Most programs focus on mental health literacy - conceptual knowledge of mental illnesses and their effects and treatment. Some also include "social inclusion" content such as rich case histories to mimic the personal experience that diminishes dispositionalism in social inference (Balcetis \& Dunning, 2008; Martin, 2010). As part of efforts to improve attitudes and knowledge about depression, it may be helpful to train a third schema to supplement "good performer" and "bad performer" schemas. This is a schema for the compromised-through-no-fault-of-theirown employee with an invisible disability who deserves sensitive handling and accommodation. Familiarity with the ways that depression manifests at work would allow managers and coworkers to activate this new and more sympathetic schema when appropriate.

Another issue concerns the relative effectiveness of general mental health literacy training versus separate training about specific illnesses such as depression, given the widely differing perceptions and stigmas that are associated with different mental disorders (e.g., depression vs. schizophrenia). Szeto and Dobson (2010) also call for research on the long term effects of mental health training on the attitudes and behavior of managers and employees, and on the effectiveness of training and other interventions on hard measures such as absenteeism, cost of 
disability claims, and average length of disability leave.

\section{Developing Manager Skills for Supporting Depressed Employees}

Positive attitudes and conceptual knowledge of depression are not enough to enable managers to deal with employees who may be suffering from depression. Procedural knowledge and interpersonal skills are also essential to sensitively explore performance problems if depression has not been disclosed, to respond to a disclosure, to demonstrate empathy and respect privacy, to encourage help seeking, to plan and implement workplace accommodation, and to manage flow-on effects for coworkers and the organization. Martin, Woods, and Dawkins (2014) discuss the development of an applied management knowledge curriculum for imparting these skills. Such a program would complement more generic training on emotional intelligence or leadership provided in business schools or by employing organizations.

In summary, safe and early disclosure of depression followed by sensitive and appropriate accommodation may help employees recover more quickly, reduce employee reputational costs and intragroup conflict, and limit organizational productivity loss, costs, and legal liabilities. I-O psychologists can contribute to the advancement of theory and practice that informs the design and evaluation of interventions to change attitudes among all organizational members, provide the conceptual and procedural knowledge that managers of employees with depression need, and develop organizational climates that support the effective management of individuals with invisible disabilities such as depression.

\section{References}

Balcetis, E., \& Dunning, D. A. (2008). A mile in moccasins: How situational experience diminishes dispositionalism in social influence. Personality and Social Psychology Bulletin, 34, 102-114.

Beck, A., Crain, A. L., Solberg, L. I., Unützer, J., Glasgow, R. E., Maciosek, M. V., \& Whitebird,
R. (2011). Severity of depression and magnitude of productivity loss. Annals of Family Medicine, 9, 305-311.

Charbonneau, A., Bruning, W., Titus-Howard, T., Ellerbeck, E., Whittle, J., Hall, S., ... Munro, S. (2005). The community initiative on depression: Report from a multiphase work site depression intervention. Journal of Occupational and Environmental Medicine, 47, 60-67.

Coppens, E., Van Audenhove, C., Scheerder, G., Arensman, E., Coffey, C., Costa, S., ... Hegerl, U. (2013). Public attitudes toward depression and help-seeking in four European countries baseline survey prior to the OSPI-Europe intervention. Journal of Affective Disorders, 150, 320-329.

Ford, M. T., Cerasoli, C. P., Higgins, J. A., \& Decesare, A. L. (2011). Relationships between psychological, physical, and behavioral health and work performance: A review and meta-analysis. Work \& Stress, 25, 185-204.

Hanges, P. J., Braverman, E. P., \& Rentsch, J. R. (1991). Changes in raters' perceptions of subordinates: A catastrophe model. Journal of Applied Psychology, 76, 878-888.

Jain, G., Roy, A., Harikrishnan, V., Shawn, Y., Dabbous, O., \& Lawrence, C. (2013). Patientreported depression severity measured by the PHQ-9 and impact on work productivity: Results from a survey of full-time employees in the United States. Journal of Occupational and Environmental Medicine, 55, 252-258.

Kessler, R., White, L. A., Birnbaum, H., Ying, Q., Kidolezi, Y., Mallett, D., \& Swindle, R. (2008). Comparative and interactive effects of depression relative to other health problems on work performance in the workforce of a large employer. Journal of Occupational and Environmental Medicine, 50, 809-816.

Martin, A. (2010). Individual and contextual correlates of managers' attitudes towards depressed employees. Human Resource Management, 49, 647-668.

Martin, A., Woods, M., \& Dawkins, S. (2014). Managing employees with mental health issues: Identification of conceptual and procedural knowledge for development within management education curricula. Academy of Management Learning and Education. http://amle.aom.org/content/early/2014/01/08/am le.2012.0287.abstract

Monteith, L. L., \& Pettit, J. W. (2011). Implicit and explicit stigmatizing attitudes and stereotypes about depression. Journal of Social and Clinical Psychology, 30, 484-505.

Plaisier, I., de Graaf, R., de Bruijn, J., Smit, J., van Dyck, R., Beekman, A., \& Penninx, B. (2012). Depressive and anxiety disorders on-the-job: The importance of job characteristics for good work functioning in persons with depressive and anxiety disorders. Psychiatry Research, 200, 382-388.

Reb, J., \& Greguras, G. J. (2010). Understanding performance ratings: Dynamic performance, attributions, and rating purpose. Journal of Applied Psychology, 95, 213-220.

Santuzzi, A. M., Waltz, P. R., Finkelstein, L. M., \& Rupp, D. E. (2014). Invisible disabilities: Unique challenges for employees and organizations. Industrial and Organizational Psychology: Perspectives on Science and Practice, 7(2), 204-219. 
Szeto, A. C. H., \& Dobson, K. S. (2010). Reducing the stigma of mental disorders at work: A review of current workplace anti-stigma intervention programs. Applied and Preventive Psychology, 14, $41-56$.

Tsuchiya, M., Kawakami, N., Ono, Y., Nakane, Y., Nakamura, Y., Fukao, A., ... Kikkawa, T. (2012). Impact of mental disorders on work performance in a community sample of workers in Japan: The World Mental Health Japan Survey 2002-2005. Psychiatry Research, 198, 140-145.

World Health Organization (WHO). (2011). Depression. Retrieved from http://www.who.int/men tal_health/management/depression/definition/en/ index.html 